\title{
Effect of curing conditions during the first 24 hours after casting on the properties of mortar mixtures
}

\author{
Ali Mardani-Aghabaglou (Main and Corresponding Author) \\ Bursa Uludag University, Department of Civil Engineering \\ Gorukle Campus, 16240, Nilufer, Bursa (Turkey) \\ ali.mardani16@gmail.com
}

\section{Süleyman Özen}

Bursa Technical University, Department of Civil Engineering

Yildirim Campus, 16330, Yildirim, Bursa (Turkey)

suleyman.ozen@btu.edu.tr

\section{Muhammet Gökhan Altun}

Bursa Uludag University, Department of Civil Engineering

Gorukle Campus, 16240, Nilufer, Bursa (Turkey)

mgaltun@yahoo.com

\author{
Manuscript Code: 1471 \\ Date of Acceptance/Reception: 27.01.2020/09.05.2019 \\ DOI: 10.7764/RDLC.19.1.68-79
}

\begin{abstract}
As it is well known, the curing method directly affects many properties of cementitious composites. In previous studies, the effect of different curing conditions on the properties of the cementitious systems has been generally investigated in the period after first 24 hours after casting. However, there are not many studies in the literature related to the effects of curing conditions on the specimens kept in mold during 24 hours after casting. In this study, strength development, ultrasonic pulse velocity (UPV) and water absorption capacity of mortar specimens subjected to steam-curing at different temperatures during keeping in mold for the first 24 hours after production were compared. In this regard, all mortar specimens were exposed to curing in a steam-curing cabin at $95 \%$ constant relative humidity (RH) under 5 different temperatures such as $20,35,50$, 65 and $80^{\circ} \mathrm{C}$ for the first 24 hours after the specimens were placed into the molds. Afterwards, the specimens were removed from the molds and cured in water conformed to the standard until the testing day. In this context, the water-cement ratio, sand-binder and slump-flow value of all mortar mixtures were kept constant as $0.485,2.75,25 \pm 2 \mathrm{~cm}$, respectively. As a result, the application of steam-curing at high temperature for the first 24 hours positively affected the 1-day compressive strength and UPV values of the mixtures, while the 3,7 and 28-day compressive strength, UPV values and the 28-day water absorption capacity of mixtures were adversely affected.
\end{abstract}

Keywords: Mortar mixtures, curing conditions, water absorption, compressive strength, ultrasonic pulse velocity.

As a known fact that cement hydration is an exothermic reaction between cement and water. There are many factors which affect the heat and the fresh properties of concrete such as the heat of hydration, the temperature of materials used in concrete production, the absorption of solar rays and the temperature of the environment. Besides, the cement hydration is also affected by parameters such as the amounts of cement components, water-binder ratio and water drain from macro and micro voids (Abbas \& Majdi, 2017).

Uncontrolled temperature and unpreventable void water loss result in thermal and shrinkage cracks in concrete. As a result of this, permeability is increased and all mechanical properties especially compressive strength, as well as durability properties of the concrete, are negatively affected (Wyrzykowski, McDonald, Scrivener \& Lura, 2015). Consequently, most of the strength and durability properties of the concrete are dependent on the hydration of cement rather than the chemical structure of the cement paste.

It is possible to control the temperature of the cementitious composites and to occur hydration reactions by proper and adequate curing. Within this context, different methods such as water curing, steam curing, covering the concrete surface with waterproofing materials are used (Beushausen \& Bester, 2016; Hiremath \& Yaragal, 2017; Ismail, Kwan \& Ramli, 2017; Zanotti, Borges, Bhutta \& Banthia, 2017). Curing type, curing duration, and curing conditions affect the fresh and hardened properties of the cementitious systems. Previous studies related to the subject are summarized below. 
Effects of different curing methods on compressive strength, flexural strength, water absorption rate and porosity of mortar mixtures are investigated by Aparicio, Martinez-Ramirez, Ranz, Fuenta \& Hernandez (2016). Fly ash, blast furnace slag and rice husk ash instead of portland cement at $50 \%$ ratio (by mass) were used as binders. Produced samples were stored for 24 hours after casting. The samples taken from the mold were exposed to different curing conditions. The first series of samples were cured in water under $23 \pm 3^{\circ} \mathrm{C}$ temperature (standard curing), the second series of samples were cured in air under $27 \pm 4^{\circ} \mathrm{C}$ temperature and $70 \% \pm 10$ relative humidity and the third series of samples were kept in water at $60^{\circ} \mathrm{C}$ for 24 hours after being removed from the mold. Afterwards, they were cured in water under $23 \pm 3^{\circ} \mathrm{C}$. The fourth series of samples were kept in water at $60^{\circ} \mathrm{C}$ for 24 hours right after being removed from the mold. They were cured in an environment with $27 \pm 4^{\circ} \mathrm{C}$ temperature and $70 \% \pm 10$ relative humidity until the testing day. According to the test results, the hot water curing at early ages was determined as an effective method for acquisition of the 1-day strength for the mixtures. This method was especially determined to be more effective in mixtures including blast furnace slag. Compressive strengths of the mixtures containing portland cement during standard curing were higher than the mixtures applied air curing at early ages. The best performance was observed in mortar mixtures to which both air and water curing applied as well as containing blast furnace. It was found out that compressive strengths of the mortar mixtures containing $100 \%$ portland cement cured both in hot water and air were higher than the mortar mixtures containing $100 \%$ portland cement exposed both to hot water and standard water curing at early ages. At later ages, mortar mixtures, cured both in hot water and air, showed the highest compressive strength compared to the other three curing methods. The best performance for the flexural strength, on the other hand, was observed in mortar mixtures containing $25 \%$ rice husk ash and $25 \%$ fly ash cured both in hot water and air for 28 days.

Ramezanianpour, Esmaeili, Ghahari \& Ramezanianpour (2014) investigated the effect of steam curing on the mechanical and durability properties of self-compacting concretes. For this purpose, the samples were exposed to 12 different steam curing treatments at different temperatures, such as $60^{\circ} \mathrm{C}$ and $70^{\circ} \mathrm{C}$ during 16,18 and 20 hours. In addition to portland cement, different types of mineral admixtures such as metakaolin, pumice and trass were used as binder. The fresh concrete properties (slump-flow diameter, T50 duration, flow loss, fresh weight per unit of volume and L-box flow) as well as the hardened concrete properties (compressive strength, capillary water absorption, surface electric conductivity and speed chlorine ion permeability tests) were determined. According to the results, the application of steam curing increased the compressive strength significantly. The fact that the temperature is higher resulted in higher initial strengths since the formation of $\mathrm{C}-\mathrm{S}-\mathrm{H}$ gel and $\mathrm{CH}$ crystals was realized more quickly. However, the effect of steam curing on the 90-day ultimate compressive strengths was not determined. Among the steam curing applications carried out in the study, the most optimal application was the steam curing for 18 hours. Compared to the other samples, the mixture with metakaolin showed the highest compressive strength in terms of the early age strength. Researchers stated that pumice, limestone, and trass materials might be used instead of metakaolin with regard to the performance. The addition of mineral additives to the mixtures increased the durability performance. Increasing the steam curing temperature from $60^{\circ} \mathrm{C}$ to $70^{\circ} \mathrm{C}$ increased the permeability of the samples. Metakaolin showed less permeability performance than pumice, while pumice showed less permeability performance than trass and limestone. The use of mineral additives in mixtures improved the electrical surface resistance in terms of permeability.

Nahata, Kholia \& Tank (2014) investigated the effect of different curing methods on the compressive strength of mortar mixtures. For this purpose, mortar mixtures with 4 different water-cement ratios $(0.45,0.50,0.55$ and 0.60$)$ were produced in accordance with ASTM C109 Standard. The sand-binder ratio in all mixtures was constant at 2.75. Different amounts of water were added to the mixtures to provide $110 \pm 5 \mathrm{~mm}$ slump-flow. The samples were cured for up to 28 days after stored in mold for 1 day. Researchers investigated 4 different curing methods. The first method is air curing. The samples were kept in an environment at room temperature for 28 days. The second method is water curing. The samples were cured in a cistern at room temperature for 28 days. The third method of curing is the saturated coating. In this curing method, which is frequently used in the building industry, such wool coatings and sack coatings as well as moisture holding materials as felt were used. Concrete surface was coated during the curing to be kept moist. The fourth method is the chemical curing. The chemical is applied to the surface of concrete. Acrylicbased, resin-based, water-based and wax-based chemical materials were used for curing. Experimental results show that acrylic-based chemicals and wax-based components provided higher strength for mortar mixtures compared to the other components. According to the researchers, the use of membranes and water-saturated coatings performed 80-90\% efficiency in terms of strength compared to the conventional water curing. The samples exposed to dry air curing showed the lowest performance in terms of strength. The researchers stated that the higher strength performance of the mixtures resulted from the prevention of water loss from the sample.

The curing method affects many properties of the cementitious composites directly. In addition to the curing method, curing time and temperature also affect the properties of the cementitious systems directly (Neupane, 
Sriravindrarajah, Baweja \& Chalmers, 2015; Turuallo \& Soutsos, 2015; Aparicio et al., 2016; Kocab, Kucharczykova, Misak, Zitt \& Kralikova, 2017; Mostefinejad, Nikoo \& Hosseini, 2016; Nasir, Al-Amoudi \& Maslehuddin, 2017; Orosz, Hedlund \& Cwirzen, 2017)

The effects of different curing conditions and curing temperatures on chlorine permeability of the concretes containing high amount of fly ash were studied by Jiang, Jiang \& Song (2017). Consequently, it was observed that high temperature affected the compressive strength, void structure and chloride permeability of concretes at early ages positively, at later ages, on the other hand, negatively.

In a similar study, Zhang, Zhang \& Yan (2016) investigated the effects of different curing temperatures on the hydration and compressive strength of concretes containing silica fume. For this purpose, two different curing methods were applied. In the first method, the mixtures were cured under $20^{\circ} \mathrm{C}$ temperature and $95 \%$ humidity in a standard curing room. In the second method, on the other hand, the mixtures were cured under $50^{\circ} \mathrm{C}$ temperature and $95 \%$ humidity in a standard curing room until the testing day after being exposed to steam curing during the first 7 days. As a result, curing at high temperatures affected the compressive strengths at early ages positively; however, it affected compressive strengths at older ages adversely.

In another study, the effects of different curing temperatures on compressive strength, water and chloride permeability, the thermal conductivity of ceramisite concretes for 1, 3, 7 and 28 days were investigated by Fan, Zhang, $\mathrm{Yu}$, Li \& Cosgrove (2017). Within this context, curing temperatures were chosen as $20^{\circ} \mathrm{C}, 40^{\circ} \mathrm{C}$ and $60^{\circ} \mathrm{C}$. Concrete samples were cured in a standard curing pool for $20^{\circ} \mathrm{C}$ as well as in anadjustable curing cabin with humidity more than $90 \%$ for $40^{\circ} \mathrm{C}$ and $60^{\circ} \mathrm{C}$ temperatures. According to the results, the 28-day compressive strengths of the specimens cured at $60^{\circ} \mathrm{C}$ were decreased considerably compared to the specimens cured at $20^{\circ} \mathrm{C}$. Mixtures cured at $40^{\circ} \mathrm{C}$, on the other hand, showed similar compressive strength to mixtures cured at $20^{\circ} \mathrm{C}$ only when the accelerator admixture was used. It is stated that the main cause is the low internal density and high porosity resulted from curing at high temperatures.

As it can be understood from the literature, various studies were carried out about the effect of different curing conditions on the mechanical and durability properties of the cementitious systems. However, the effect of different curing conditions in which the samples were exposed to after their removal from the mold ( 24 hours) was examined in almost all studies. No specific studies were found in the literature related to the effect of curing conditions in which the samples were kept in the mold for 24 hours on the properties of cementitious systems. In this study, samples were exposed to curing in a steam curing cabin at $95 \%$ constant relative humidity (RH) under 5 different temperatures for the first 24 hours after the specimens were placed into the molds. Afterwards, the specimens were removed from the molds and cured in water conformed to the standard until the testing day. Thus, the effect of the different first-24hour curing temperatures on strength development, UPV values and water absorption rates of the mortar mixtures was investigated.

\section{Methodology}

\section{Materials}

In this study, CEM I 42.5R type portland cement in accordance with EN 197-1 Standard was used as a binder. The physical, mechanical properties and chemical composition of the cement provided by the manufacturer are given in Table 1.

During mortar mixture production, one type of crushed limestone aggregate with $4 \mathrm{~mm}$ maximum grain size was used as aggregate. Specific gravity and water absorption values of the aggregate used in this study and shown in Table 2 were determined in accordance with EN 1097-6 Standard. Sieve analysis of the aggregates given in Table 3 was performed according to EN 206-1 Standard.

A type of polycarboxylate based high range water reducing admixture (HRWR) was used in order to achieve the expected target flow in this study. Some properties of the admixture provided by the manufacturer are shown in Table 4. 
Table 1. Chemical composition, mechanical and physical properties of cement. Source: Self-Elaboration.

\begin{tabular}{|c|c|c|c|c|}
\hline \multirow{2}{*}{$\begin{array}{l}\text { Item } \\
\mathrm{SiO}_{2}\end{array}$} & \multirow{2}{*}{$\frac{(\%)}{18.86}$} & \multicolumn{3}{|c|}{ Physical properties } \\
\hline & & Specific gravity & & 3.15 \\
\hline $\mathrm{Al}_{2} \mathrm{O}_{3}$ & 5.71 & \multicolumn{3}{|c|}{ Mechanical properties } \\
\hline $\mathrm{Fe}_{2} \mathrm{O}_{3}$ & 3.09 & \multirow{4}{*}{ Compressive strength (MPa) } & 1-day & 14.7 \\
\hline $\mathrm{CaO}$ & 62.70 & & 2-day & 26.80 \\
\hline $\mathrm{MgO}$ & 1.16 & & 7-day & 49.80 \\
\hline $\mathrm{SO}_{3}$ & 2.39 & & 28-day & 58.5 \\
\hline $\mathrm{Na}_{2} \mathrm{O}+0.658 \mathrm{~K}_{2} \mathrm{O}$ & 0.92 & \multicolumn{3}{|l|}{ Fineness } \\
\hline $\mathrm{Cl}^{-}$ & 0.01 & Blaine specific surface $\left(\mathrm{cm}^{2} / \mathrm{g}\right)$ & & 3530 \\
\hline Insoluble residual & 0.32 & Residual on 0.045 mm sieve (\%) & & 7.6 \\
\hline Loss on ignition & 3.20 & & & \\
\hline Free $\mathrm{CaO}$ & 1.26 & & & \\
\hline
\end{tabular}

Table 2. Specific gravity and water absorption capacity of limestone aggregate. Source: Self-Elaboration.

\begin{tabular}{cccc}
\hline \multicolumn{2}{c}{ Aggregate } & Bulk SSD specific \\
Type & Size $(\mathrm{mm})$ & $\begin{array}{c}\text { Absorption } \\
\text { capacity }(\%)\end{array}$ \\
\hline Limestone & $0-4$ & 2.68 & 1 \\
\hline
\end{tabular}

\begin{tabular}{l} 
Table 3. Particle size distributions of aggregates. Source: Self-Elaboration. \\
\cline { 2 - 2 } \begin{tabular}{lc} 
Sieve size & Percent passing (\%) \\
$(\mathrm{mm})$ & $0-4 \mathrm{~mm}$ \\
\hline 31.5 & 100 \\
16 & 100 \\
8 & 100 \\
4 & 100 \\
2 & 77.5 \\
1 & 49.3 \\
0.5 & 32 \\
0.25 & 12.9 \\
0.125 & 2.5 \\
\hline
\end{tabular}
\end{tabular}

Table 4. Properties of high range water reducing admixture (HRWR). Source: Self-Elaboration.

\begin{tabular}{|c|c|c|c|c|c|}
\hline Type & $\begin{array}{l}\text { Density } \\
\left(\mathrm{gr} / \mathrm{cm}^{3}\right)\end{array}$ & $\begin{array}{l}\text { Solid content } \\
(\%)\end{array}$ & $\mathrm{pH}$ value & $\begin{array}{c}\text { Chloride } \\
\text { content (\%) }\end{array}$ & $\begin{array}{l}\text { Alkali content } \\
\qquad\left(\mathrm{Na}_{2} \mathrm{O}\right)(\%)\end{array}$ \\
\hline $\begin{array}{l}\text { Polycarboxylate-ether based high } \\
\text { range water reducing admixture }\end{array}$ & 1.097 & 36.35 & 3.82 & $<0.1$ & $<10$ \\
\hline
\end{tabular}

\section{Mix design and testing procedure}

Water-cement and sand-binder ratios were kept constant as 0.485 and 2.75 in all mortar mixtures produced in accordance with ASTM C109 Standard. Material amounts which are used during mortar mixture productions are shown in Table 5. Flow values of all mixtures were kept constant as $25 \pm 2 \mathrm{~cm}$. As shown in Table $5,0.5 \mathrm{wt} \% \mathrm{HRWR}$ was used by cement weight in order to provide the target flow value.

Table 5. Mix proportions of all mortar mixtures. Source: Self-Elaboration.

\begin{tabular}{|c|c|c|c|c|}
\hline Cement & Water & $\begin{array}{c}\text { Aggregate } \\
(0-4 \mathrm{~mm})\end{array}$ & $\begin{array}{c}\text { High range } \\
\text { water reducing } \\
\text { admixture }\end{array}$ & Flow value \\
\hline $500 \mathrm{~g}$ & $242.5 \mathrm{~g}$ & $1375 \mathrm{~g}$ & $2.5 \mathrm{~g}$ & $240 \mathrm{~mm}$ \\
\hline
\end{tabular}


Flow testing of the mortar mixtures was performed in accordance with ASTM C1437 Standard. 1, 3, 7 and 28-day compressive strength and ultrasonic pulse velocity (UPV) values were determined in accordance with ASTM C109 and ASTM C597 Standards, respectively. The 28-day water absorption ratios of the mixtures were measured in accordance with the EN 1097-6 Standard. All measurements were carried out on $50 \mathrm{~mm}$ cube specimens.

\section{Curing conditions}

Prepared mortar mixtures were cured in a curing cabin under different conditions (different temperatures and $95 \%$ $\mathrm{RH}$ ) for 24 hours after casting. Afterthat, the specimens were removed from the molds and cured in water at $20^{\circ} \mathrm{C}$ until the testing day. In this study, mortar specimens were designated regarding the temperatures of the steam curing cabin in which they were kept during the first 24 hours. The designations of the specimens are summarized in Table 6.

\begin{tabular}{cccc}
\multicolumn{5}{c}{ Table 6. Sample codes and cure conditions. Source: Self-Elaboration } \\
\hline Mixture & Stages & Curing Time (day) & Temperature $\left({ }^{\circ} \mathrm{C}\right)$ \\
\hline T20 & 1. Stage (in molds) & 1 & 20 \\
& 2. Stage (in water) & $2,6,27$ & 20 \\
T35 & 1. Stage (in molds) & 1 & 35 \\
& 2. Stage (in water) & $2,6,27$ & 20 \\
T50 & 1. Stage (in molds) & 1 & 50 \\
& 2. Stage (in water) & $2,6,27$ & 20 \\
T65 & 1. Stage (in molds) & 1 & 65 \\
& 2. Stage (in water) & $2,6,27$ & 20 \\
T80 & 1. Stage (in molds) & 1 & 80 \\
& 2. Stage (in water) & $2,6,27$ & 20 \\
\hline
\end{tabular}

As stated earlier, 5 different curing conditions were applied in this study. Details of the applied curing conditions shown in Figure 1 are summarized below.

T20: The mortar specimens were cured in a steam curing cabin at $20^{\circ} \mathrm{C}$ and $95 \% \mathrm{RH}$, T35: The mortar specimens were cured in a steam curing cabin at $35^{\circ} \mathrm{C}$ and $95 \% \mathrm{RH}$, T50: The mortar specimens were cured in a steam curing cabin at $50^{\circ} \mathrm{C}$ and $95 \% \mathrm{RH}$, T65: The mortar specimens were cured in a steam curing cabin at $65^{\circ} \mathrm{C}$ and $95 \% \mathrm{RH}$, T80: The mortar specimens were cured in a steam curing cabin at $80^{\circ} \mathrm{C}$ and $95 \% \mathrm{RH}$ for the first 24 hours shortly after being placed into the mold and then at $20^{\circ} \mathrm{C}$ in the lime-saturated water until the testing day.
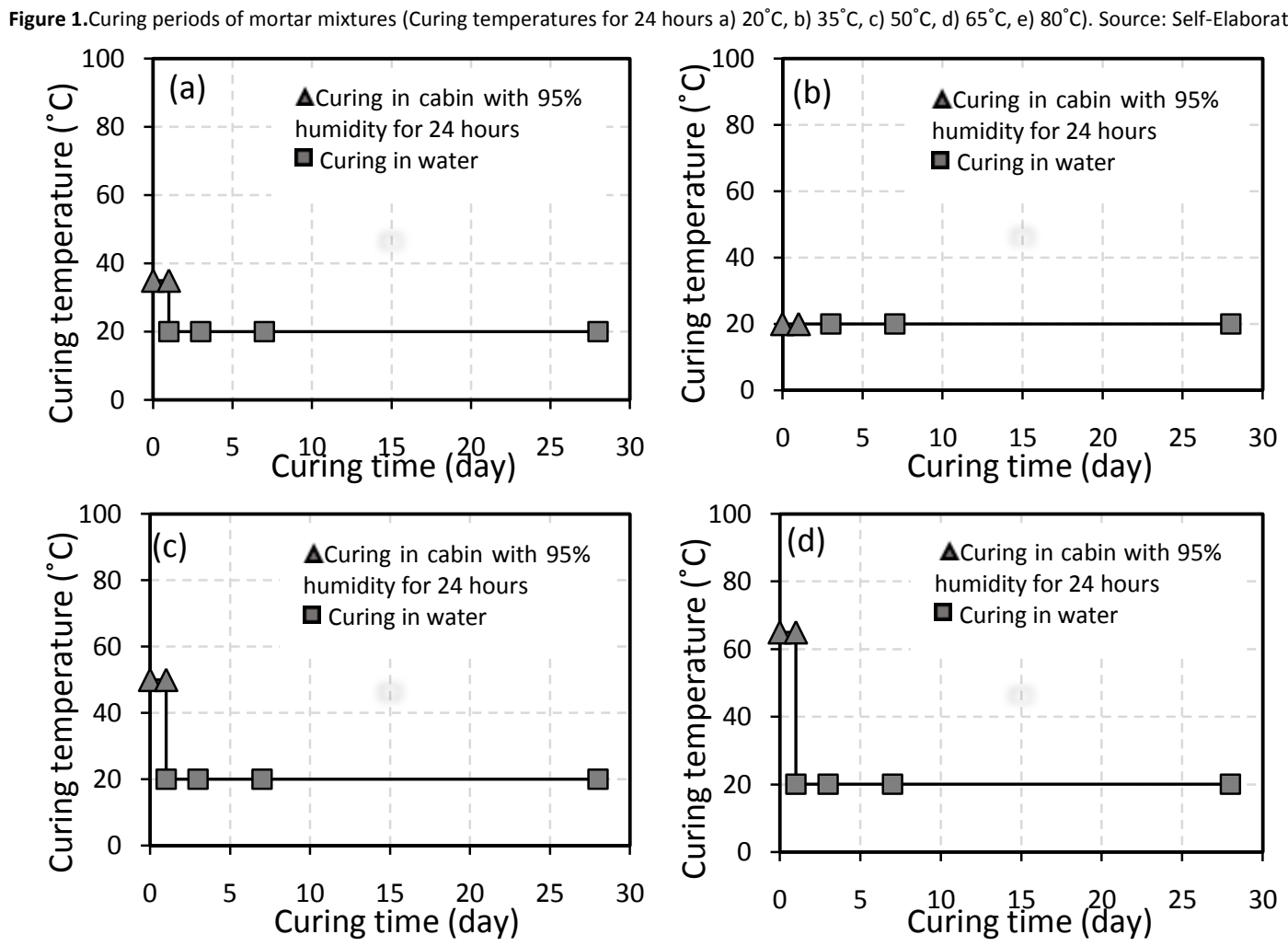


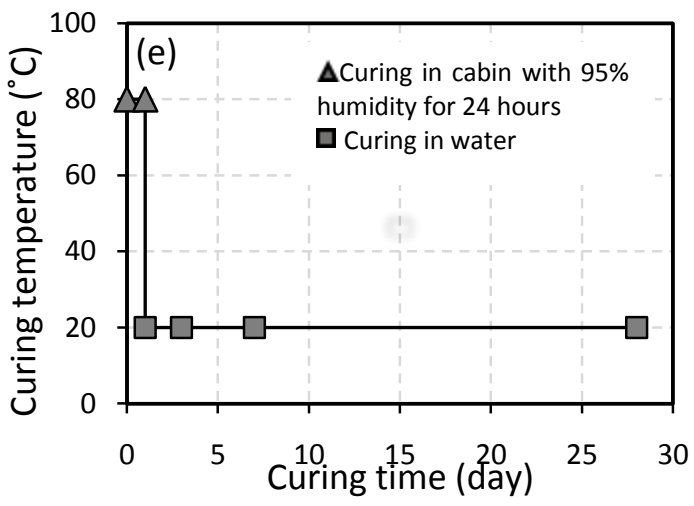

Results and Discussion

\section{Compressive Strength}

In this study, T20 mixture was considered as the control mixture kept in a curing cabin at $20^{\circ} \mathrm{C}$ and $95 \%$ relative humidity for 24 hours immediately after the mortar was placed in mold. Results of the other mixtures were compared in reference to the $T 20$ mixture.

Compressive strengths of the mortar mixtures are given in Figure 2. The 1, 3, 7 and 28-day relative strengths of the mixtures in accordance with the control mixture (T20) are given in Figure 3.

As it can be seen from the results in Figure 2, the compressive strength of all mixtures increased by time regardless of the first 24-hour curing temperature. The 1-day compressive strength test of the specimens exposed to steam curing at different temperatures for 24 hours in mold was performed immediately after demolding.

Steam-cured at $35^{\circ} \mathrm{C}$ for 24 hours, T35 mixture showed the highest strength when the 1-day compressive strengths of the mixtures were compared. The 1-day compressive strength of the T35 mixture is found to be nearly $60 \%$ higher than that of the control mixture (T20). T50, T65 and T80 mixtures showed higher compressive strength compared to the control mixture as $48 \%, 49 \%$ and $42 \%$, respectively. When the 3 -day compressive strength results were analysed, the T20 mixture showed the lowest performance in terms of 1-day strength but the highest performance in terms of the 3-day strength. The T35 mixture showed similar behavior with the T20 mixture in terms of the 3-day compressive strength. Demonstrating 30\% less strength than that of the control mixture, T80 mixture obtained the lowest 3-day compressive strength. The difference between these compressive strengths of the mixtures became more distinctive by time. The 3-day compressive strengths of T50 and T65 mixtures were $20 \%$ lower than the control mixture.

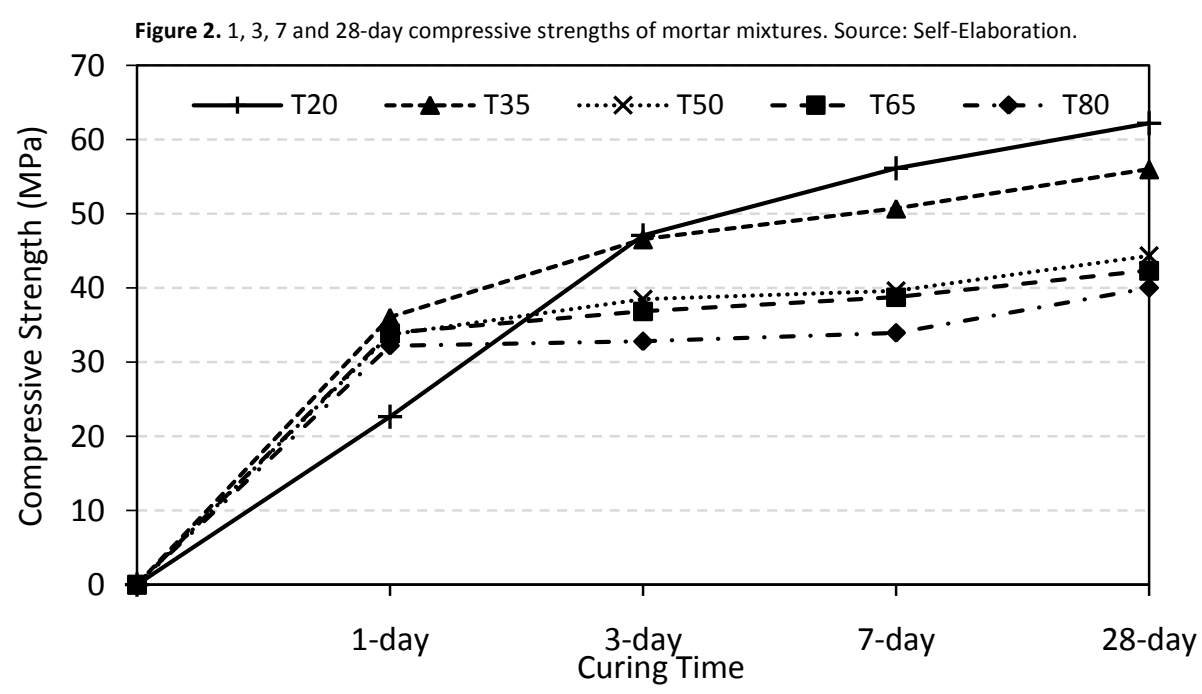


Figure 3. Relative compressive strengths of mortar mixtures according to T20 mixture (Control Mixture) (a) 1-day strength, (b) 3-day strength, (c) 7-day strength, (d) 28-day strength. Source: Self-Elaboration.
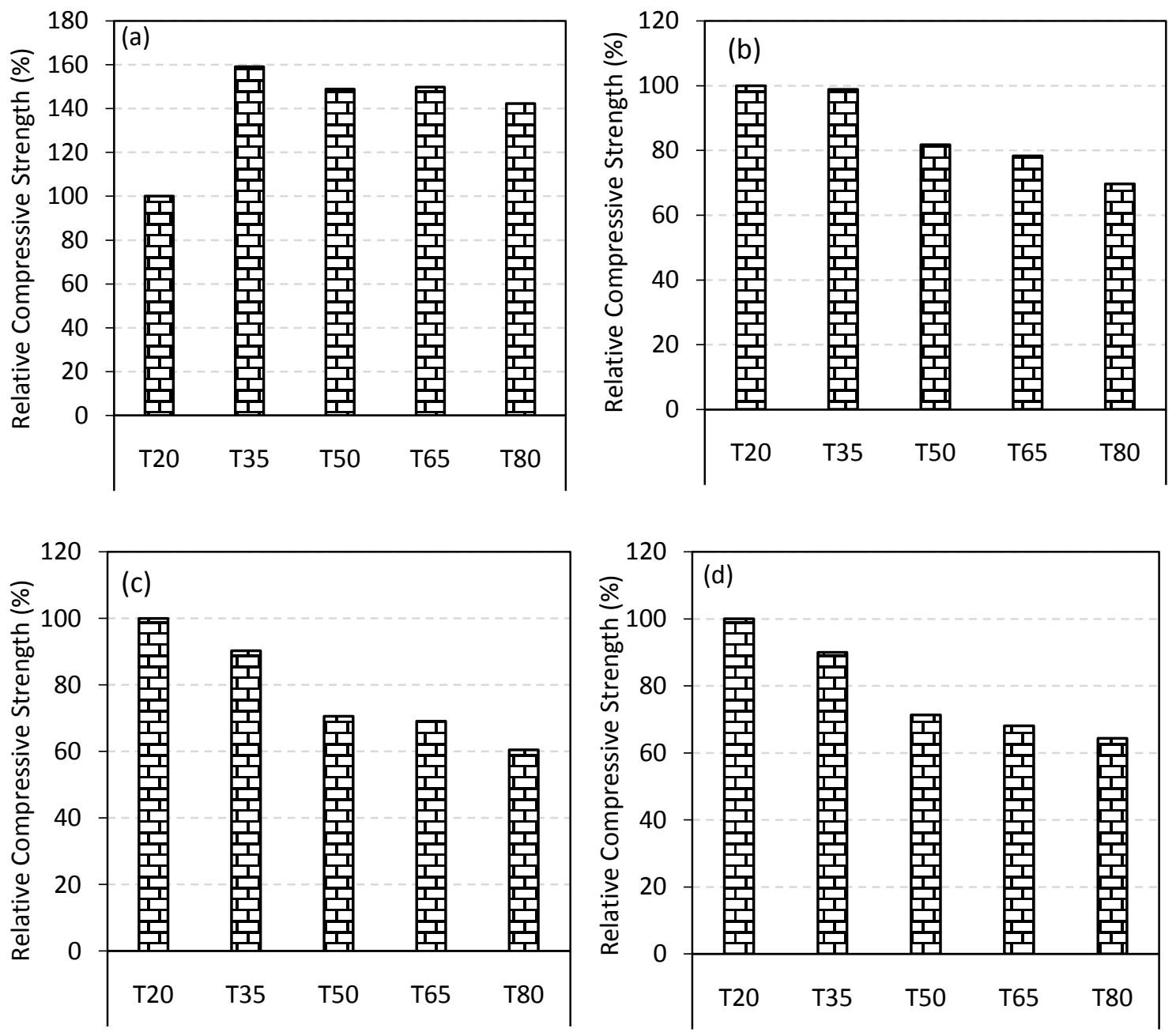

As it can be seen from Figure 2, the 7 and 28-day compressive strength developments of T35, T50, T65 and T80 mortar mixtures were in a similar tendency to that of the control mixture. The results show that the T20 mixture demonstrated the highest performance in terms of 7 and 28-day compressive strength. Accordingly, it was determined that the lowest performance among mixtures belongs to the T80 mixture with $40 \%$ lower strength than the control mixture. T35, T50 and T80 mixtures showed 10, 71 and 68\% lower strength than that of the control mixture, respectively.

Figure 2 shows that whereas there was an increase of approximately $147 \%$ between the 1-day and the 7-day compressive strengths of the control mixture (T20), the increase in compressive strength of T80 mixture was only $5 \%$. The increase ratios for T65, T50 and T35 mixtures were as 14\%, 10\% and 41\%, respectively. Within this regard, implementing steam curing at higher temperatures than the standard in the first 24 hours showed a positive effect on the 1-day compressive strength of the mixtures. However, it was determined that steam curing at high temperatures showed a negative effect on compressive strength after the first day.

This study shows that one of the most significant factors affecting the development of mortar compressive strength is steam curing. Implementation of steam curing plays an important role on the hydration and the microstructure formation of the cement (Matschei \& Glasser, 2010).

Test results reveal that the 1-day compressive strength of the mixtures is directly related to the steam curing under maximum temperature. That increase in the 1-day compressive strength is thought to result from the temperature increase leading a rising hydration rate in cement particles. It is considered that calcium silicate hydrate gel (C-S-H gel), which directly affects the hardened concrete strength, occurs more rapidly than that of normal curing conditions due to the high temperature and humidity during steam curing under fresh condition (Richardson, 2004). 
$\alpha-\mathrm{C}-\mathrm{S}-\mathrm{H}$ gel with lower density and higher void ratio occurs as a result of the rapid formation of the $\mathrm{C}-\mathrm{S}-\mathrm{H}$ gel. Therefore, the later age strength of the cementitious system decreases and the durability property of the system is affected negatively (Yazıcı \& Arel, 2016).

The fact that the speed formation of C-S-H gel results in the loss of stability and its formation into $\alpha$-C-S-H gel, which is an intenser crystal structure. That causes deformation of the porous structure of $\mathrm{C}-\mathrm{S}-\mathrm{H}$ gels and thus an increase in the number of capillary breaks. As a result, the presence of more capillary pores in the cement mixture affected the properties of the mixture negatively. For these reasons, the ultimate compressive strength and durability of concrete mixtures steam-cured are lower than that of the concrete mixtures cured under normal conditions.

Mineral admixture use was proposed in order to reduce this negative effect resulting from the steam curing. The C-S$\mathrm{H}$ gels formed by the use of mineral admixtures show more crystallized and less calcium-containing structure. The density of concrete containing mineral admixtures shows no much change and the reduction in ultimate strength can be minimized (Soroka, Jaegermann \& Bentur, 1999; Yazıcı, Aydın, Yiğiter \& Baradan, 2016).

Provided the pre-curing is performed at a low temperature and accurate ratios, the $\mathrm{C}-\mathrm{S}-\mathrm{H}$ gel and $\mathrm{CH}$ crystals are going to begin to fill the internal pores gradually by time. However, steam curing applications at high temperatures and ratios can be filling the pores in mortar structure in small quantities. Besides, such an increase in the steam curing time may cause C-S-H gel layer formations with small pores and damage mechanisms on the interfacial transition zone (ITZ) in concrete (Hwang, Khatib, Lee, Lee \& Khayat, 2012; Ramezanianpour et al., 2014).

In some studies, the compressive strength of specimens cured at high temperatures is reported to be $15-50 \%$ lower than that of specimens cured as standard due to curing temperature. Water in mixture plays an important role in terms of the compressive strength decrease. As the temperature increases, the water in concrete spreads more than aggregates and cement particles. Thus, more voids and micro-cracks are formed in the concrete and the interfacial transition zone is weakened. As a result, decreases in the compressive strength of the mixtures can be observed (Neville, 1995; Ho, Chua \& Tam, 2003; Yazıcı et al., 2005; Yazıcı et al., 2016).

\section{Water Absorption}

The 28-day water absorption ratios of the mortar mixtures are given in Figure 4. The lowest water absorption ratio among the mortar mixtures was determined in the T20 mixture. T20 and T35 mixtures showed very similar behaviors in terms of water absorption. The water absorption ratio of these two mixtures was measured as $5 \%$. The T80 mixture was determined to be the mixture with the highest water absorption rate by absorbing $40 \%$ more water than the control mixture (T20). As a known fact that the excessive amount of water absorption of the mixture is an indication of the excessive amount of void volume in the mixture (Mehta, 1986). Void volume is one of the most critical factors directly affecting the compressive strength of mixtures (Neville, 1995). Therefore, the mixtures with high water absorption ratio are expected to have low compressive strength. The expected inverse proportion between the compressive strength and the water absorption ratio was also observed in the mortar mixtures produced in this study. It can be seen from Figure 5 that there is a strong inverse linear relationship between the 28-day compressive strength and water absorption ratio of the mixtures. For instance, the T80 mixture belongs to the highest water absorption ratio and the lowest 28-day compressive strength.

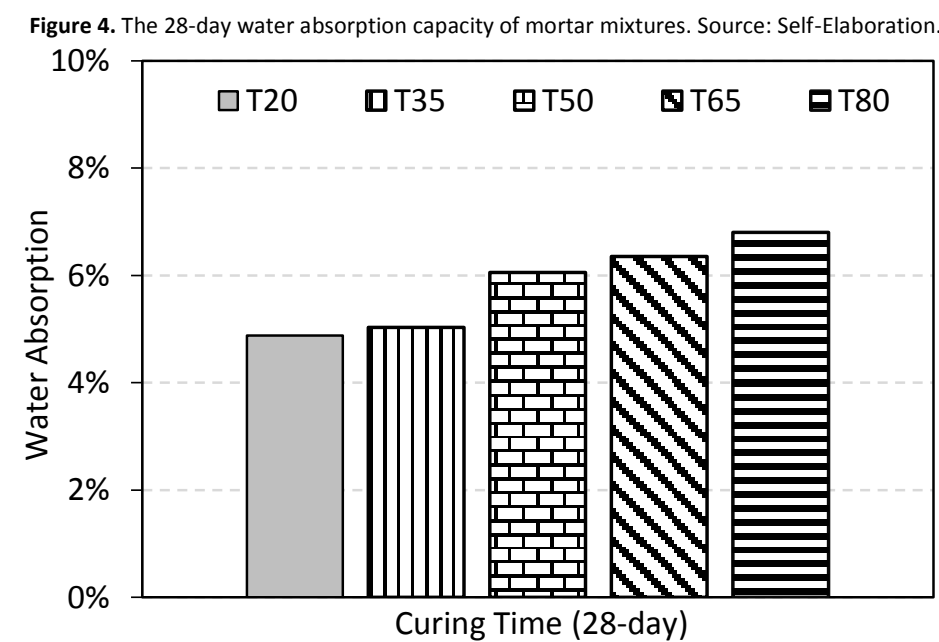




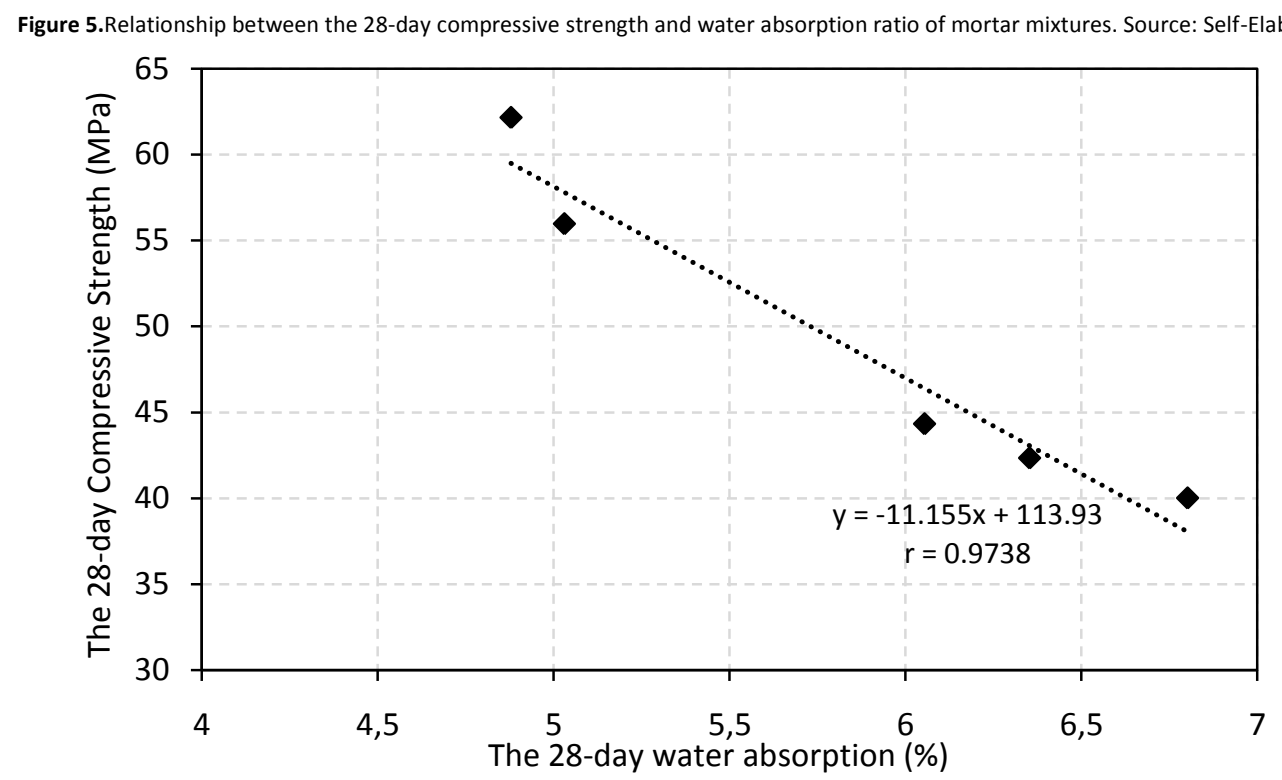

\section{Ultrasonic Pulse Velocity}

The 1, 3, 7 and 28-day ultrasonic pulse velocity test results of mortar mixtures are shown in Figure 6 . Each value was determined by calculating the average of 3 measurements. As it can be seen from Figure 6 , regardless of the curing conditions, the ultrasonic pulse velocity (UPV) values of the mixtures increased by time due to increasing the strength.

The 1-day UPV of the T20 mixture was about 5\% lower than the other mixtures. However, the T20 mixture showed a higher UPV value than the other mixtures for the 3-day and the later UPV measurements. The increase in temperature of steam curing for 24 hours affects UPV values at 3 days and later negatively. As a result of the increase in the steam curing temperature, the 3, 7 and 28 -day UPV values decreased by $1-7 \%$ compared to the control mixture.

Leslie \& Cheesman (1949) and Feldman (1977) classified concrete quality according to UPV values in their study. This classification is given in Table 7. According to this classification given in Table 7, concrete quality is excellent when the UPV value of the concrete is higher than $4.5 \mathrm{~km} / \mathrm{s}$, good when it is between 3.6 and $4.5 \mathrm{~km} / \mathrm{s}$, normal when it is between $3.0-3.6 \mathrm{~km} / \mathrm{s}$, weak when it is between $2.1-3.0 \mathrm{~km} / \mathrm{s}$, too weak when it is under $2.1 \mathrm{~km} / \mathrm{s}$.

\begin{tabular}{cc}
$\begin{array}{c}\text { Table 7. Classification of concrete quality according to UPV. } \\
\text { Source: Leslie et al. (1949); Feldman(1977). }\end{array}$ \\
\hline UPV (m/s) & Quality \\
$>4500$ & Excellent \\
\hline $3600-4500$ & Good \\
$3000-3600$ & Normal \\
$2100-3000$ & Weak \\
$<2100$ & Too Weak \\
\hline
\end{tabular}

According to the results in this study, all mortar mixtures with the 1 and 3-day UPV values between 3.9-4.4 km/s can be classified as good quality mixtures. According to this classification, the 7 and 28-day T20 and T35 mixtures are classified as "excellent" quality while 7 and 28-day T50, T65 and T80 mixtures can be classified as "good" quality.

The ultrasonic pulse velocity is one of the non-destructive test methods for evaluating the compressive strength and homogeneity of mortar mixtures (Mehta, 1986). The ultrasonic pulse velocity is directly related to the void structure of hydrated $\mathrm{C}-\mathrm{S}-\mathrm{H}$ gel and $\mathrm{CH}$ crystal structure in the mixtures. The transmission of sound waves can vary depending on many factors such as the type and amount of aggregate as well as the amount, distribution and size of voids. It is expected that the UPV value and compressive strength can be low in a cementitious system with high void volume (Ramezanianpour et al., 2014). In this regard, it can be understood from Figure 7 that there is a robustlinear relationship between UPV and compressive strength of mortar mixtures in this study. 


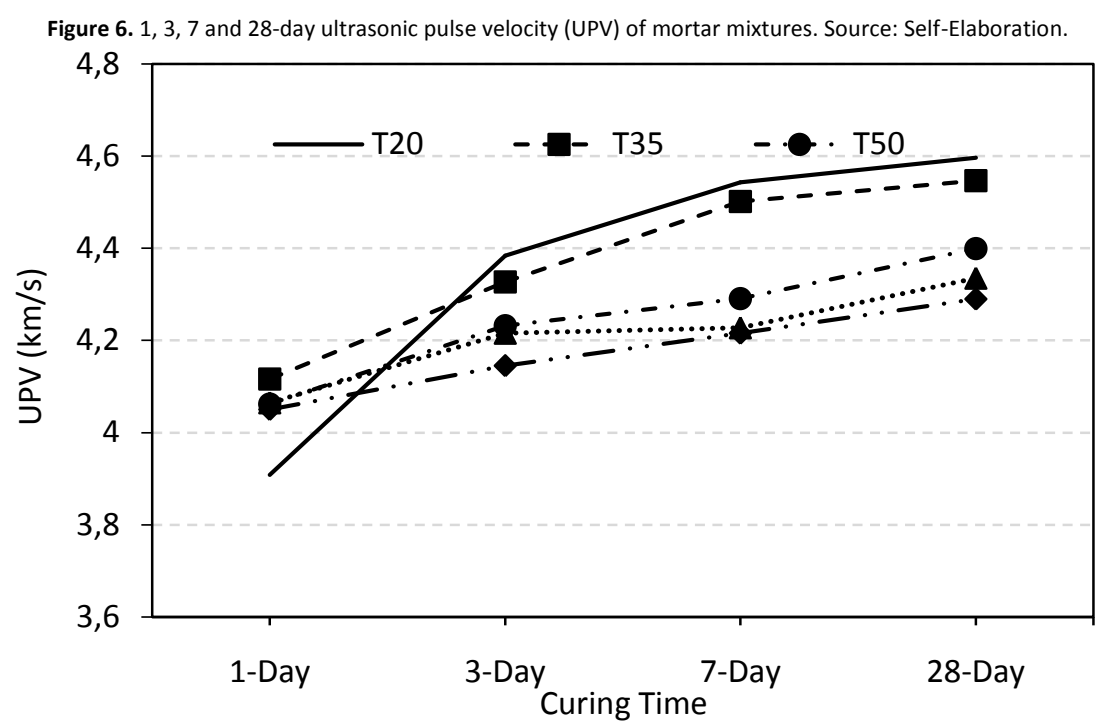

Figure 7. Relationship between the compressive strength and water absorption capacity of mortar mixtures. Source: Self-Elaboration

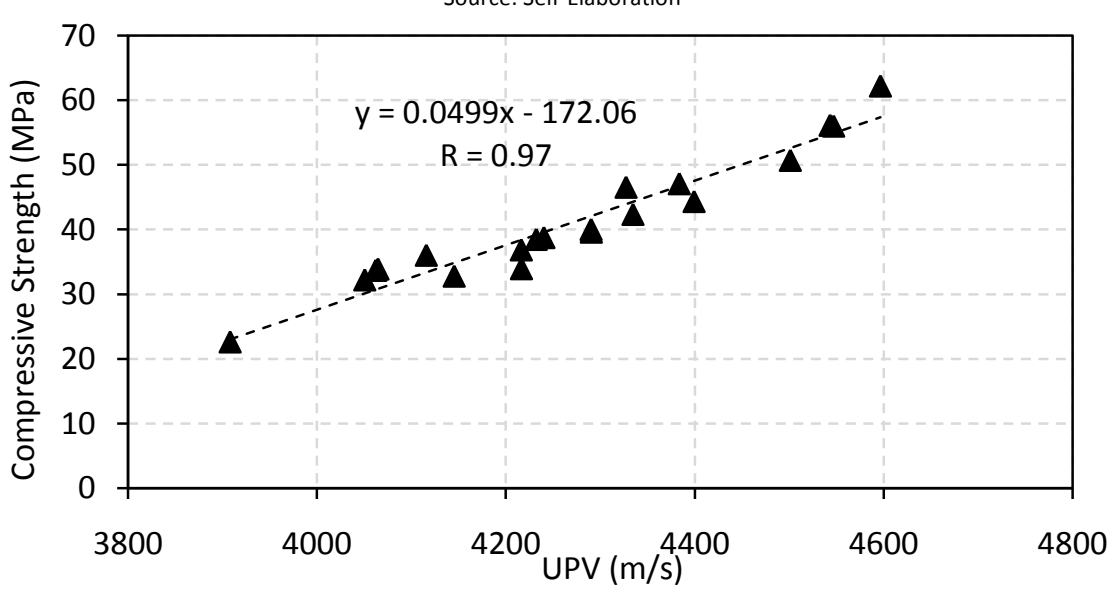

The following conclusions were obtained with regard to the materials and methods used in this study.

The 1-day compressive strength of specimens cured at $20^{\circ} \mathrm{C}$ for 24 hours after placement into the mold was lower than that of specimens cured at $35,50,65$ and $80^{\circ} \mathrm{C}$ for 24 hours. Nevertheless, the specimen cured at $20^{\circ} \mathrm{C}$ for 24 hours after 3 days showed the highest strength than the other mixtures.

The specimen cured at $80^{\circ} \mathrm{C}$ for 24 hours showed the lowest compressive strength for the later ages after 3 days. This negative effect on the compressive strength of steam curing at high temperatures became more prominent by time. The 28-day compressive strength of the specimens cured at $80^{\circ} \mathrm{C}$ for 24 hours was $50 \%$ lower than that of specimens cured at $20^{\circ} \mathrm{C}$.

The 28-day compressive strength performance of the specimens was affected negatively by the increase in the 24 hour curing temperature from $20^{\circ} \mathrm{C}$ to $80^{\circ} \mathrm{C}$. This negative effect is thought to be due to the formation of $\mathrm{C}$-S- $\mathrm{H}$ gel with more void and nonhomogeneous structure with the increasing steam-curing temperature at early ages (first 24hour period after casting).

It was observed that there is an inverse proportional relationship between the water absorption ratios and the compressive strengths of the mortar mixtures. As the steam curing temperature increased, there were also an increase in the water absorption ratios depending on the rising void. In this context, the mixture steam-cured at $80^{\circ} \mathrm{C}$ included the highest 28 -day water absorption ratio, while the mixture steam-cured at $20^{\circ} \mathrm{C}$ had the lowest 28 -day water absorption ratio. 
It was found out that there is a polynomial proportional relationship between ultrasonic pulse velocity and compressive strength of mortar mixtures. The 1-day UPV value of mixture cured at $20^{\circ} \mathrm{C}$ was lower than that of other mixtures. However, this mixture showed the highest UPV value for the 3-day and later ages compared to other mixtures.

The decrease in the UPV values of the mixtures was detected with an increase at the initial curing temperature for 24 hours just as the measured other properties.

Considering the quality classification of concrete according to UPV values, the 1 and 3-day mortar mixtures can be classified as "good" quality, the 7 and 28 -day specimens of the mixtures exposed to steam curing at $20^{\circ} \mathrm{C}$ and $35^{\circ} \mathrm{C}$ as "excellent" quality, the 7 and 28 -day mixtures steam cured at $50^{\circ} \mathrm{C}, 65^{\circ} \mathrm{C}$ and $80^{\circ} \mathrm{C}$ as "good" quality.

\section{Acknowledgments}

The authors would like to thank Bursa-Beton Ready Mixed Concrete Plant and Polisan Construction Chemicals Company authorities for their kind assistance in providing the cement, aggregate and water reducing admixture as well as determining the chemical composition, physical and mechanical properties of these products. Besides, the first author gratefully acknowledges the support provided by Uludag University Scientific Research Projects Centre (BAP) in Turkeyunder grant number AYP(MH)-2016/16.

Abbas, Z. H. \& Majdi, H. S. (2017). Study of Heat of Hydration of Portland Cement Used in Iraq. Case Studies in Construction Materials, 7, 154-162.

Aparicio, S., Martínez-Ramírez, S., Ranz, J., Fuente, J. V. \& Hernández, M. G. (2016). Microstructural and mechanical properties study of the curing process of self-compacting concrete. Materials \& Design, 94, 479-486.

Beushausen, H. \& Bester, N. (2016). The influence of curing on restrained shrinkage cracking of bonded concrete overlays. Cement and Concrete Research, 87, 87-96.

Fan, L., Zhang, Z., Yu, Y., Li, P. \& Cosgrove, T. (2017). Effect of Elevated Curing Temperature on Ceramsite Concrete Performance. Construction and Building Materials, 153, 423-429.

Feldman, R.F. (1977). Non-Destructive Testing of Concrete, CBD-187, National Research Council of Canada, Ottawa, Ontario. Available from http://web.mit.edu/parmstr/Public/NRCan/CanBldgDigests/cbd187_e.html.

Hiremath, P. N. \& Yaragal, S. C. (2017). Effect of different curing regimes and durations on early strength development of reactive powder concrete. Construction and Building Materials, 154, 72-87.

Ho, D. W. S., Chua, C. W. \& Tam, C. T. (2003). Steam-cured concrete incorporating mineral admixtures. Cement and Concrete Research, 33 (4), 595601.

Hwang, S. D., Khatib, R., Lee, H. K., Lee, S. H. \& Khayat, K. H. (2012). Optimization of steam-curing regime for high-strength, self-consolidating concrete for precast, prestressed concrete applications. PCl journal, 57 (3), 48-62.

Ismail, S., Kwan, W. H. \& Ramli, M. (2017). Mechanical strength and durability properties of concrete containing treated recycled concrete aggregates under different curing conditions. Construction and Building Materials, 155, 296-306.

Jiang, P., Jiang, L. \& Song, J. Z. Z. (2017). Influence of Temperature History on Chloride Diffusion in High Volume Fly Ash Concrete. Construction and Building Materials, 144, 677-685.

Kocab, D., Kucharczykova, B., Misak, P., Zitt, P. \& Kralikova, M. (2017). Development of the elastic modulus of concrete under different curing conditions. Procedia Engineering, 195, 96-101.

Leslie, J. R. \& Cheesman, W. J. (1949). An ultrasonic method of studying deterioration and cracking in concrete structures. Journal of the American Concrete Institute, $46(9), 17-36$.

Matschei, T. \& Glasser, F. P. (2010). Temperature dependence 0 to $40^{\circ} \mathrm{C}$ of the mineralogy of Portland cement paste in the presence of calcium carbonate. Cement and Concrete Research.40 (5), 763-777.

Mehta, P. K. (1986). Concrete. Structure, properties and materials, Prentice Hall, New Jersey, USA.

Mostefinejad, D., Nikoo, M. R. \& Hosseini, S. A. (2016). Determination of optimized mix design and curing conditions of reactive powder concrete (RPC). Construction and Building Materials, 123, 754-767.

Nasir, M., Al-Amoudi, O. S. B. \& Maslehuddin, M. (2017). Effect of placement temperature and curing method on plastic shrinkage of plain and pozzolanic cement concretes under hot weather. Construction and Building Materials, 152, 943-953. 
Neupane, K., Sriravindrarajah, R., Baweja, D. \& Chalmers, D. (2015). Effect of curing on the compressive strength development in structural grades of geocement concrete. Construction and Building Materials, 94, 241-248.

Neville, A.M. (1995). Properties of Concrete, Wiley, New York, USA.

Nahata, Y., Kholia, N. \& Tank, T. G. (2014). Effect of curing methods on efficiency of curing of cement mortar. APCBEE procedia.,9, $222-229$.

Orosz, K., Hedlund, H. \& Cwirzen, A. (2017). Effects of variable curing temperatures on autogenous deformation of blended cement concretes. Construction and Building Materials, 149, 474-480.

Ramezanianpour, A. M., Esmaeili, K., Ghahari, S. A. \& Ramezanianpour, A. A. (2014). Influence of initial steam curing and different types of mineral additives on mechanical and durability properties of self-compacting concrete. Construction and Building Materials, 73, 187-194.

Richardson, I. G. (2004). Tobermorite/jennite-and tobermorite/calcium hydroxide-based models for the structure of CSH: applicability to hardened pastes of tricalcium silicate, $\beta$-dicalcium silicate, Portland cement, and blends of Portland cement with blast-furnace slag, metakaolin, or silica fume. Cement and Concrete Research, 34(9), 1733-1777.

Soroka, I., Jaegermann, C. H. \& Bentur, A. (1978). Short-term steam-curing and concrete later-age strength. Matériaux et Construction, 11(2), 93-96.

Turuallo, G. \& Soutsos, M. (2015). Supplementary cementitious materials: Strength development of self-compacting concrete under different curing temperature. Procedia Engineering, 125, 699-704.

Wyrzykowski, M, McDonald, P. J., Scrivener, K. L. \& Lura, P. (2017). Water Redistribution within the Microstructure of Cementitious Materials due to Temperature Changes Studied with 1H NMR. The Journal of Physical Chemistry C. 121 (50), 27950-27962.

Yazıcı, H., Aydın, S., Yiğiter, H. \& Baradan, B. (2005). Effect of steam curing on class C high-volume fly ash concrete mixtures. Cement and Concrete Research, $35(6), 1122-1127$.

Yazıcı, Ş. \& Arel, H. Ş. (2016). The Influence of Steam Curing on Early-Age Compressive Strength of Pozzolanic Mortars. Arabian Journal for Science and Engineering, 41(4), 1413-1420.

Zanotti, C. Z., Borges, P. H. R., Bhutta, A. \& Banthia, N. (2017). Bond strength between concrete substrate and metakaolin geopolymer repair mortar: Effect of curing regime and PVA fiber reinforcement. Cement and Concrete Composites, 80, 307-316.

Zhang, Z., Zhang, B. \& Yan, P. (2016). Hydration and Microstructures of Concrete Containing Raw or Densified Silica Fume at Different Curing Temperatures. Construction and Building Materials, 121, 483-490. 